\title{
Motivation fostering through gaming technologies
}

\author{
N.V. Ageenko ${ }^{1 *}, A . A$. Rybkina $^{2}$, and N.V. Startseva ${ }^{3}$ \\ ${ }^{1}$ Samara State Technical University, Samara, Russia \\ ${ }^{2}$ Samara Branch of Moscow City Pedagogical University, Samara, Russia \\ ${ }^{3}$ Samara state university of social sciences and education, Samara, Russia
}

\begin{abstract}
Modern educational strategies are focused on the formation of new students' life attitudes and personal characteristics: today it is important to develop cognitive skills and promote educational motivation. The ways of fostering motivation of students at the initial stage are discussed in the paper. In this article, special attention is paid to the theoretical issues of teaching English, moreover, methodological foundations of teaching English with the help of gaming technology are reviewed. The analysis of psychological, pedagogical, methodological literature made it possible to reveal the theoretical basis of the problem and create a specific approach for stimulating students' motivation. The article presents a set of developed didactic games that enhance motivation in the process of teaching the English language at the primary stage. The authors have studied in detail the problem of using game and play activity at English lessons, have identified its positive effect on learning, training and revising of educational material. A number of didactic requirements for games are examined, thus identified the necessity to take into account the age of learners, their interests, as well as the correct approach to involve each student in the game. The most relevant game technologies are considered separately, and their effectiveness (or inefficiency) is confirmed by means of an experiment. The authors prove the obtained results with reference to statistic sign test as it is considered to be one of the most effective and promising in scientific-analytical and reflexive research. Authors' theoretical and experimental research has shown the possibility of forming motivation of junior students by means of using didactic games and substantiated the importance of their use to achieve the goal.
\end{abstract}

\section{A problem statement}

Social and economic transformations, new technologies application, expanding international relations require enhancing the system and practice of education. The issues of improving the quality of the learning process, the implementation of the educational and developmental potential of a foreign language as a training course act as priority areas.

* Corresponding author: prof-ped.gpa@,mail.ru 
Currently, one of the main problems of the methodology of teaching a foreign language is new technologies application, which makes it possible to create conditions for students' motivation fostering. At the initial stage of learning a foreign language, motivation plays an important role in the development of speech and language skills. The age characteristics of primary school age students determine a smooth transition from play to learning activities, during which the motives for achieving the goal of learning are formed. It is known that the use of gaming technologies at the lesson helps to increase the cognitive activity of students. Educational game programs are a modern and effective method of teaching a foreign language at the initial stage of learning, ensuring not only the assimilation of new knowledge, skills and abilities, but also the formation of the student's personality $[1,2,3]$.

The use of traditional ways and means of influencing students in order to introduce them to the culture of the country of the target language is being revised, new technologies are being introduced, one of which is game technology. It should also be noted that while maintaining a sufficiently high motivation, there is a decrease in cognitive interest in learning a foreign language. This phenomenon occurs due to the fact that students face some difficulties that seem unachievable to them. Game and play activity, being one of the methods that stimulates educational and cognitive activity, allows a teacher to use all levels of knowledge assimilation. Consequently, the interest in the use of gaming technologies at foreign language lessons is not accidental.

\subsection{The objective of the work}

Psychological characteristics of younger students give them advantages in learning a foreign language, as they absorb new knowledge indirectly and subconsciously. The ways that students obtain and comprehend information are various: visual, auditory, kinesthetic. Students' cognitive development is related to the general intellectual development. The best motivation for further learning for junior students is a sense of success. Motivation plays a huge role in the study of any subject, especially foreign languages. Success largely depends on what motives students pursue in the process of learning any foreign language. According to I.A. Zimnjaja, a motive determines, stimulates, prompts a person to perform some action, included in the activity determined by this motive [4]. The motivational component is associated with students' attitude of to the content, process of activity, includes motives, interests and needs of students in the game. The motivational component ensures their activity in the game, connection with other activities. Motivation is laid in the very process of the game. $[5,6]$ The role of game in foreign language lessons is enormous, as it allows you to make the educational process attractive and interesting for students. However, one should focus on the fact that the place of play and game technology in the educational process, the combination of game and learning elements largely depend on the teacher's understanding of the functions and classification of didactic games. [1,2] Due to the fact that we form a motivational component, motivation is formed through the use of gaming technologies. Primary school age implies a period in which games in the learning process are of great interest to students. Game at this age is second only to learning activities. The participation of younger students in didactic games contributes to their selfaffirmation, develops perseverance, desire for success and various motivational qualities.

\section{Results of the research}

In order to test the effectiveness of the use of gaming technologies as a way to increase motivation at English lessons in primary school, an experimental study was carried out, which consisted of the ascertaining and formative stages. 
At the ascertaining stage of the experiment, the students were divided into two groups in accordance with the principle of identity (the identity of all the main initial, important from the point of view of this study, characteristics of the control and experimental groups). The number of trainees in each group was 10 people. In accordance with this principle, students should study in the same form (in our case, we conducted the study in grade 3 B) and have approximately the same level of learning motivation. The choice of two groups later made it possible to determine the dynamics of the process of the formation of the motivational component in the same form, where, within the framework of the formative experiment, classes were built on the basis of the use of play and game technologies in the experimental group, and in the control group - without involving their capabilities.

The experimental study was carried out in the natural conditions of the educational process with a relatively homogeneous team of students divided into two groups. In this form, lessons were conducted according to the textbook "Spotlight 3" (English in Focus. Grade 3. Textbook.) [7], but in the experimental group, in contrast to the control, training games were used, developed on the basis of the classification of games according to I.A. Zimnjaja [4].

The purpose of the ascertaining stage was to determine the level of motivation among primary school students. To achieve the goal, a self-selected test of 10 tasks (by NG Luskanova) was carried out [8].

Each answer matching the key in the line:

- "high level", estimated at 2 points;

- "average level" - 1 point;

- "low level" - 0 points.

Then the total score is calculated.

Students' levels of school motivation are determined according to the following ranges:

- 1 - 6 points corresponds to a low level of motivation formation;

- 7 - 12 points corresponds to the average level of motivation formation;

- 13 - 18 points corresponds to a high level of motivation formation.

After calculating the total score, the level of students' educational motivation in the experimental group was determined.

The test results showed that the majority of students in the experimental group are characterized by an average level of motivation. A high level was characteristic to only one student, and a low level was characteristic to four ones.

The same test was offered to the students of the control group.

After calculating the total score, we determined the level of educational motivation among students in the control group.

Thus, we can conclude that the majority of students in the control group also had an average level of educational motivation. A high level of proficiency was also characteristic to only one student, and a low level to three ones. So the test results showed that the students of the experimental and control groups had approximately the same levels of motivation.

In accordance with the hypothesis that the use of didactic games in English lessons helps to increase the motivation of students, didactic games were developed for working with students in grade 3 "B".

For the development of these games, the classification of I.A. Zimnjaja was implemented. From this classification, for the formation of motivation of primary school age, there are the types of games that relate to:

- physical (motor);

- psychological;

- cognitive, educational, developing;

- reproductive, productive, creative; 
- outdoor games with a verbal component;

- competition games.

Using the game at English lessons is an effective way to improve the quality and productivity of teaching a foreign language. This gives good results, increases the interest of students at the lesson, allows them to concentrate their attention on mastering speech skills in the process of a natural situation, communication during the game.

Didactic games were developed taking into account the psychological and pedagogical characteristics of primary school age.

Themes for the games were taken on the basis of planning English lessons according to the textbook "Spotlight" ("English in focus") for grade 3 by authors N.I. Bykova, J. Dooley, M.D. Pospelova, V. Evans.

This teaching material was created taking into account the requirements of the Federal State Educational Standard for foreign languages, and also complies with the standards developed by the Council of Europe in the field of teaching foreign languages. This is evidenced by the distinctive badge on the cover of the textbook. This is the first Russian teaching materials, which is a joint product of the Russian publishing house "Prosveshchenie" and the British publishing house "Express Publishing".

After analyzing the textbook "Spotlight - 3", it can be said that the learner-centred approach to teaching a foreign language, which the authors of the teaching materials adhere to, provides special attention to the interests, individual characteristics and real abilities of students. Taking into account the psychological, typological and age characteristics of junior students, the textbook uses exercises and tasks that are diverse in form and content. The exercises are arranged in a sequence that is most conducive to the most successful assimilation of the material. The material is organized in such a way that it allows you to regularly repeat the main active lexical items. Thus, within the framework of this educational and methodological complex, the implementation of didactic games in the classroom in order to increase the motivation of younger students will be the most successful.

Here are examples of games developed for primary school students aimed at increasing motivation.

Physical (movement) game:

Name: "Bring me"

Purpose of the game: to form a communication skill on the topic "A day off"

Equipment: cards with names of hobbies

Game progress:

In the classroom, cards with the names of hobbies (tennis, dancing, fishing, shopping etc.) are laid out. The facilitator asks the children to bring him a card, naming it or describing it in English. Whoever finds and brings this item first wins. For example: Bring me a card that shows - swimming.

This type of game was used in the English lesson on the topic "We're having a great time!", As a reinforcement of vocabulary.

Psychological game:

All psychotechnical exercises are based on the interaction of students in the process of performing this or that action, which liberates them in communication situations, makes students' speech free and easy, contributes to the expression of their own opinions in a foreign language, which inspires students to further study the subject, activates cognitive processes, contributing to the positive formation of psychological health. In accordance with this, we have developed a game of this type, which we used in the beginning of the English lesson while studying the vocabulary.

Name: "My hobby is..."

Purpose of the game: to form communication skills on the topic "A day off" 
Equipment: cards with various types of hobbies

Game progress:

A student with the main role is chosen by lot or at will. He chooses a card with a type of hobby that interests him (reading, coking, swimming, riding a bike, singing etc.). In a minute, he needs to get used to this role so that the rest of the students can guess what is written on the card. The card is given to the guesser. The winner is the one with the most cards.

With the help of this psychological game, relaxation was carried out in which students were asked to answer the questions: "How do you feel? What feelings did you experience in the first minutes of the lesson? What did you like? What was new for you?", Which helped to relieve tension, evoke positive emotions, good mood, which served to activate mental activity, improve the assimilation of the material.

Educational game:

Name: "Puzzle"

Purpose of the game: to form communication skills on the topic "A day off"

Equipment: sets of cards

Game progress:

Each participant is given 3 identical sets of cards, which depict various activities in the park (playing soccer, sleeping, drinking Coke, riding a bike, flying a kite etc.). The teacher shows the first whole card, then removes it and asks the children to assemble the same one from those cut images that they have. All samples are shown sequentially. It is important to remove the sample every time after demonstrating it, not leaving it to correlate and copy while the children are solving a mental problem. Children must assemble by themselves, without relying on the sample.

If the participants perform this task at different speeds, it is advisable to move to an individual display of samples, which will maintain the interest of the participants in this game.

This game is aimed at developing memory, thinking.

Creative game:

Name: "What does it look like?"

Purpose of the game: to form communication skills on the topic "Day off"

Equipment: blank sheets of paper and colored pencils

Game progress:

Pupils sit down at desks arranged in advance in a circle. The driver thinks of any hobby (For example: reading, coking, swimming, singing etc.) according to the studied vocabulary and begins to draw something. Pupils take turns calling the hobby (no looking), the one who calls the type of hobby the last wins.

The presented game is of a creative nature, contributing to enlarge the vocabulary.

An active game with a verbal component:

Name: "Snowballs"

Purpose of the game: to form communication skills on the topic "A day off"

Equipment: blank sheets of paper and pens

Game progress:

The teacher hands out small sheets of paper to the students and asks them to write one word or phrase at a time on a specific topic (or from the text with which they worked). After the students do this, they should make a "snowball" out of their sheets and, simultaneously, at the teacher's command, throw them in the "target" drawn on the board in the form of a circle. Then the participants of the game must, at the command of the teacher, quickly take one of the snowballs and make up a sentence with it or give an explanation for this word, and the rest must guess what word it is.

Competition game: 
Name: "Hobby"

Purpose of the game: to form a communication skill on the topic "A day off"

Equipment: blank sheets of paper and pens

Game progress:

Students are divided into two teams. The given words must be combined according to their meaning. The team which makes more sentences correctly wins.

free time, magazines, newspapers, books, things, stamps, stickers, cards, watch TV, cartoons, computer games, chess, football, music, the songs.

Group 1: read magazines, newspapers, books;

Group 2: collect things, stamps, stickers, cards;

Group 1: watch TV, cartoons;

Group 2: play computer games, chess, football;

Group 1: listen to music, the songs;

Group 2: We like to play computer games and play football. What about you?

Group 1: We like to listen to music and play chess.

This didactic game is aimed at improving lexical speaking skills.

Analysis of the results of experimental work

As a result of the formative experiment, the students of the experimental group should have increased the level of educational motivation in comparison with the control group. In order to consider the dynamics of the formation of the motivational component in two groups, a control test was carried out, similar to the one given at the beginning of the experiment (by M.V. Matyukhina) [9].

After calculating the total score, we determined the level of students' motivation formation of the experimental group.

1 - 6 points corresponds to a low level of motivation formation;

7 - 12 points corresponds to the average level of motivation formation;

13 - 18 points corresponds to a high level of motivation formation.

As a result of the experiment, it was noted that in the experimental and control groups the number of students with a high level of educational motivation increased, and the number of students with a low level decreased. But the number of students in the control group with a high level of motivation is inferior to the number of students in the experimental group. A low level of educational motivation as a result of the experiment became more characteristic for the students in the control group.

The results of the experiment showed that the level of motivation formation among students in the experimental group, where didactic games were used, increased by $30 \%$.

The reliability of the results obtained was substantiated using the method of statistical processing (statistical criterion of signs). All this gives reason to believe that the introduction of the complex of didactic games developed by us into the practice of conducting English classes in primary school contributes to the formation of motivation.

\section{Conclusions}

The problem of using play activity at English lessons have been studied in detail, its positive impact on the assimilation, development and repetition of educational material have been identified. Thus, analyzing the use of game forms of the lesson, we came to the conclusion that their systematic implementation contributes to an increase in the knowledge of not only the student, but also the teacher, expands his methodological tools, stimulates search, initiative, makes the teacher as a person more interesting and artistic. Therefore, students experience joy of learning, their horizons become broader, independence in judgments is deeper, and the students' personality is brighter. In the course of the research, physical, psychological, educational, creative, outdoor games with a verbal component and 
competition games based on the classification of I.A. Zimnjaja in the study of English, in order to form the motivational component of primary students. The reliability of the obtained results was substantiated using the method of the statistical criterion of signs, which made it possible to assert that didactic games contribute to the formation of a motivational component.

Analysis of theoretical literature allowed us to determine that the age of primary school students is the most favorable for learning a foreign language, because this period is marked with the most susceptible for the language acquisition, and allows to master the basic communicative skills.

One of the most important psychological factors in the success of teaching a foreign language to primary school students is the presence of a positive motivation to learn a foreign language. Considering the problems of motivation and finding ways to form it, simplification of its understanding is unacceptable, since motivation formation is not the introduction of ready-made, from the outside motives and goals of teaching. The formation of motives is, first of all, creating conditions for the manifestation of inner urges to learn, awareness by their students and further self-development of motivational-value spheres.

To form motivation for learning activities at the initial stage, it is not very important just to organize the educational process but also to develop the students' cognitive interest and creative activity. Among various methods of organizing classes, the greatest interest among students is caused by game and play technologies. The game is an effective teaching tool that activates students' mental activity, makes the learning process attractive and interesting, fosters motivation and encourages students to master a language.

\section{References}

1. L. Botturi., S. Loh, Once Upon a Game: Rediscovering the Roots of Games in Education, Games: Purpose and Potential in Education, Morehead, 1-20 (2018)

2. V.V. Khokhlova, Sociocultural interaction in an educational game, University education, 146 (2014)

3. T.M. Mikhailenko, Game technologies as a type of pedagogical technologies, Pedagogy: traditions and innovations, 1, 140-146 (2011)

4. I.A. Zimnjaja, Pedagogical Psychology, 480 (1997)

5. M. Deen, Games Autonomy Motivation and Education, Eindhoven, Fontys University of Applied Sciences and Eindhoven University of Technology, 268 (2019)

6. A.J. Elliott, C.S. Dweck, Handbook of competence and motivation, Guilford Press, 120 (2018)

7. N.I. Bykova, J. Dooley, M.D. Pospelova, V. Evans, "Spotlight 3" English in Focus, Education, 3, 121 (2012)

8. A.G. Luskanova, Methods of determining school motivation, The science, 25 (2007)

9. M.V. Matjukhina, Motivation for learning of primary school students, Pedagogy, 144 (1984) 